\title{
La economía: ¿ciencia o algo parecido a la ciencia?
}

\author{
Economics: Science or something like science?
}

\author{
José C. Valenzuela Feijóo* "
}

\section{Resumen}

El ensayo plantea una interrogante: ¿se puede sostener, con alguna seguridad, que la economía es una ciencia? Algunos rechazan el aserto, otros lo aprueban y no pocos indican que se trata de una "semi-ciencia". El ensayo repasa primero los elementos que ponen en duda el estatuto científico de la disciplina. Luego se concentra en el examen del paradigma académicamente dominante: el neoclásico. Se señala que esta corriente funciona con una perspectiva básicamente apriorística aunque se declara empirista-popperiana. Asimismo, aunque se declara neutral y "positiva”, ajena a valores y preferencias, opera con un claro "deber-ser" que, en los hechos, favorece a algunos grupos sociales y perjudica a otros. En lo básico, este paradigma no satisface los cánones que se supone debe satisfacer una ciencia en forma. Para el autor, la economía, a la fecha, no es todavía una ciencia plena.

Palabras clave:

- Ciencia

- Metodología

- Clásicos

\section{Abstract}

The essay raises a question: can hold, with some confidence, that economics is a science? Some reject the assertion, others do not approve and few indicate that it is a "semi-science". The essay first reviews the elements that question the scientific status of the discipline. Then concentrated on the examination of dominant academic paradigm: Neoclassical. It is noted that this current work with a priori perspective but basically declares Popperian empiricist. Also, although is neutral and "positive" values and preferences of others, operates with a clear "should be" that, in fact, favors some groups and hurts others. In basics, this paradigm does not satisfy the canons that is supposed to satisfy a science in shape. For the author, the economy, to date, there is still a full science

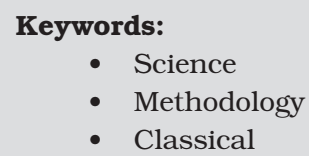

- Classical

JEL: A10, A11, B12

\section{E1 problema}

Pensemos en la siguiente situación: en una escuela universitaria de física, en los cursos de física teórica, llega un profesor que en vez de enseñar las físicas de Newton y de Einstein, desempolva algunos viejos textos griegos y se dedica a enseñar con gran convicción la física de Aristóteles. No tratándose de un curso sobre historia de las teorías físicas, la segura y unánime reacción de la comunidad académica sería de estupor primero y de abierto rechazo después. La razón de esta reacción sería muy clara: no podemos enseñar errores, falacias, falsedades. Detrás de esto, a su vez, podemos visualizar una realidad propia de las ciencias plenamente constituidas: la existencia de criterios y normas de verificación de hipótesis que permiten sostener con total certeza que tal o cual hipótesis se ha demostrado como falsa. 
¿Podemos operar en teoría económica con la misma seguridad? Parece claro que no. En nuestra disciplina abundan las "físicas aristotélicas" pero no hay ningún acuerdo sobre cuál es su contenido. Para algunos, es el modelo de Walras; para otros, el de Marx. ¿Por qué se da esta situación? Al ir al grano: ¿cuál es el efectivo estatuto de nuestra disciplina? ¿Es una ciencia o algo que sólo parece una ciencia y que en el fondo no lo es? ¿Tal vez una semi-ciencia? Por cierto, la respuesta a la pregunta qué debe estudiar un economista no es independiente de las respuestas que se den a preguntas como las que acabamos de plantear. Y aunque el espacio disponible no sea muy holgado, trataremos de bordar algunas mínimas y elementales reflexiones sobre el tema. Primero, haremos referencia a tres aspectos que ponen en duda el estatuto científico de la disciplina: i) los ciclos de dominación teórica; ii) la coexistencia de múltiples escuelas o corrientes; iii) la ambigüedad del corpus teórico neoclásico. Luego, nos preguntaremos por las causas de una cientificidad tan escasa, para arribar después a algunas primeras y muy preliminares conclusiones.

\section{Ciclos hegemónicos}

Permítasenos recordar un viejo texto de Alvin Hansen, probablemente escrito hacia 1947. En él podemos leer juicios como los siguientes: "la teoría keynesiana general de la determinación de la renta (...) hace que el análisis basado en el estudio MV parezca como un curioso armatoste superviviente de los tiempos de Maricastaña”. ${ }^{1}$ En el mismo texto, se presenta la evolución de la recepción del ideario de Keynes como sigue:

- "Primera fase: ¡Que absurdo! ¿Es posible que alguna persona sensata crea esas cosas?"

- "Segunda fase: esas ideas son peligrosas; deberían prohibirse".

- “Tercera fase: ¡Claro! ¡Eso lo sabe todo el mundo!, ¿quién lo pondría en duda?". ${ }^{2}$

Por la misma época, Paul Samuelson se refiere al impacto de la aparición de la Teoría General en términos líricos: "fue una bendición estar vivo en aquel amanecer, ipero ser joven era el mismo cielo!”. Agrega Samuelson que "la General Theory se apoderó de la mayoría de los economistas menores de

${ }^{1}$ Alvin Hansen, "Keynes acerca de la política económica"; en S. E. Harris edit., La nueva ciencia económica, p. 170; Madrid, 1995.

${ }^{2}$ A. Hansen, op. cit., p. 166. 
treinta y cinco años con la inesperada virulencia con que una nueva dolencia ataca y diezma a los miembros de una tribu aislada de isleños oceánicos. Los economistas de más de cincuenta años resultaron ser completamente inmunes a la enfermedad. Con el tiempo, la mayoría de los que se encontraban en edades intermedias comenzaron a sufrir la fiebre sin saber, con frecuencia -o sin querer reconocer- que la padecían". ${ }^{3}$

Por cierto, en la historia de la disciplina, la visión neoclásica -aparentemente muy deteriorada por el mensaje keynesiano- no fue la inicial o primeriza. Antes de ésta, la corriente dominante fue la escuela clásica (y antes, fisiócratas y mercantilistas), la que se tipificaba por su visión macroscópica y dinámica, por concentrar su atención en los problemas de la acumulación y el desarrollo, algo por supuesto más atractivo que el equilibrio general estático de un Walras. Según se ha escrito, "no fue tanto un defecto de la teoría pura como un cambio en el clima político lo que puso fin al reinado de los clásicos. Las doctrinas clásicas, aún en su forma más liberal, subrayan la función económica de las clases sociales y los conflictos de intereses entre ellas. A finales del siglo XIX, el foco del conflicto social se había desplazado del antagonismo del capitalista y el terrateniente a la oposición de los trabajadores a los capitalistas. El miedo y el horror suscitados por la obra de Marx se vieron exacerbados por el efecto que en toda Europa produjo la Comuna de París de 1871. Las doctrinas que sugerían conflictos ya no eran deseables. Las teorías que distraían la atención, apartándola del antagonismo de las clases sociales, alcanzaban una buena acogida". ${ }^{4}$ En el plano académico oficial, el dominio neoclásico fue absoluto y se extendió por más de medio siglo. Pero no resistió el impacto de la gran crisis de 1929-1933. Según ya apuntamos, a partir de los cuarenta irrumpe el keynesianismo y se transforma en el enfoque dominante o hegemónico.

¿Qué trajo Keynes a la teoría económica? ¿Cuál fue su aporte fundamental? Por cierto, no es el caso entrar aquí a un análisis detallado y a la vez fundamentado. No es ése el propósito de este trabajo, amén de que al respecto aún hoy se observa una polémica bastante agria, algo que en parte también se origina por las indudables ambigüedades que existen de su obra. Pero, para nuestros propósitos, nos basta recordar dos o tres aspectos muy elementales.

Lo primero, es el renacimiento de la macroeconomía, sepultada e inexistente en el pensamiento neoclásico previo. ${ }^{5}$ En realidad, el mismo vocablo

${ }^{3}$ Paul Samuelson, La Teoría General, en S. E. Harris, op. cit., p. 128.

${ }^{4}$ Joan Robinson y John Eatwell, Introducción a la economía moderna, p. 54. FCE, Madrid, 1976.

${ }^{5}$ En la actualidad se habla del modelo macroeconómico clásico, pero: i) en los tiempos de la 
"macroeconomía" no se conocía antes de la Teoría General y aunque de hecho no es manejado por Keynes (se le atribuye a Samuelson o a R. Frisch), el vocablo adquiere carta de ciudadanía a partir del citado opus mágnum. Por cierto, no se trata sólo de una novedad semántica y ni siquiera tan sólo de un cambio en el foco de la atención preferente. El punto mayor es otro: el rompimiento que se insinúa contra el atomismo metodológico que tipifica a la visión neoclásica: la suma de las partes es igual al todo. Por ello, si se analiza el caso individual (consumidor, firma) el problema teórico global está resuelto, pues la agregación se entiende como una suma simple. En Keynes, se insinúa una postura radicalmente opuesta; esto, en el sentido de que el todo determina a las partes y no al revés.

Es sabido que Keynes se preocupó poco o nada de los problemas microeconómicos. Pero si lo anterior es correcto, es evidente que de la Teoría General también debería desprenderse todo un programa de reconstrucción de la microeconomía: romper con el enfoque neoclásico convencional y desarrollar un enfoque coherente con la nueva visión macroeconómica. Curiosamente Keynes aceptó explícitamente el grueso de la microeconomía tradicional, una inconsecuencia nada infrecuente en sus escritos. De hecho, el keynesianismo ulterior se manejó con esa grande inconsecuencia o dualidad -algo muy subrayado y criticado por los nuevos neoclásicos- entre las visiones macro y micro del funcionamiento económico. ${ }^{6}$

Cuando hablamos de renacimiento de la macroeconomía, empleamos el vocablo en un sentido elástico y que para evitar equívocos, conviene explicar. Los clásicos (Smith, Ricardo, Mill, Marx) manejaron una visión estructuralista -más que la del mismo Keynes- y también concentraron su atención en el aspecto macro de la economía. Pero su máxima preocupación fue el desarrollo económico, es decir, la dinámica estructural de largo plazo del sistema. En Keynes, esta preocupación está ausente. Cuando, vg., analiza la inversión, se preocupa de ella como factor de la demanda y deja de lado su impacto en las capacidades instaladas de producción. En este sentido se ha sostenido que su análisis es estático (algo que puede suscitar discusión) y, en todo caso, que es de corto plazo. Es decir, no se preocupa del desarrollo sino de los niveles de actividad económica en el corto plazo. Por lo mismo,

hegemonía neoclásica jamás se explicitó algo semejante; ii) se trata de una construcción efectuada a partir del ejemplo keynesiano, aunque obviamente manejando hipótesis neoclásicas.

${ }^{6}$ Este problema está ausente en Kalecki. El gran economista polaco rechazó completamente la teoría macroeconómica neoclásica. Autores como el mismo Kalecki, Bain, Sylos-Labini y otros, han trabajado una microeconomía alternativa. En el bando conservador, la dualidad original entre macro (Keynes) y micro (neoclásica) se ha superado por la vía de suprimir la macroeconomía (caso vg., de Barro). 
si la teoría clásica constituye el "alimento" natural de las estrategias, la de Keynes es la teoría que suele alimentar mejor a las políticas económicas. En breve, entre Keynes y los clásicos no existe identidad y, por ello, eso del renacimiento es algo más bien relativo. ${ }^{7}$

Un tercer y grueso elemento a destacar se refiere a la noción de un capitalismo inestable. En la visión neoclásica, se plantea que el sistema se autorregula espontáneamente y que, al igual que en la mecánica clásica, tiende a volver una y otra vez a una posición de equilibrio que -por ello- es también estable. Se añade que en esa posición se utilizan los recursos económicos a plenitud y del modo más eficiente. Keynes rechaza abruptamente esta visión, (por cierto, terriblemente mítica y apologética) y plantea que "en condiciones de laissez-faire, quizá sea imposible evitar las fluctuaciones amplias en la ocupación sin un cambio trascendental en la psicología de los mercados de inversión, cambio que no hay razón para esperar que ocurra. En conclusión, afirmo que el deber de ordenar el volumen actual de inversión no puede dejarse con garantías de seguridad en manos de los particulares". ${ }^{8}$ Dada esta apreciación, se deduce que la ley del valor (entendida como el principio regulador general de una economía de mercado) debe ser complementada por el principio de la intervención estatal.

Muy poco tiempo después de publicada la Teoría General, apareció el célebre artículo de Hicks, "Mr. Keynes and the Classics: A Suggested Interpretation". ${ }^{9}$ Este ensayo, junto al trabajo de Hansen, ${ }^{10}$ encajaron a Keynes en un esquema de equilibrio general y proporcionaron una codificación pedagógica que, al final de cuentas, fue mucho más leída que la misma Teoría General. En el intento, se perdieron aspectos muy relevantes del mensaje original, aspectos sobre los cuales la insistencia de autores como Joan Robinson fue especialmente tenaz. Uno de ellos se refiere a la dimensión temporal del análisis, lo que los post-keynesianos han dado a llamar "tiempo histórico". Al decir de Moore, "la esencia de una economía que opera en el tiempo histórico es que el pasado está dado y no puede ser cambiado y, que el futuro es incierto y no puede ser conocido". ${ }^{11}$ La observación, apunta al usual supuesto walrasiano de previsión perfecta de los agentes económicos $y$, en este sentido, es impecable. No obstante, al menos -dado que no podemos entrar aquí a un análisis detallado- habría que señalar que la crítica

\footnotetext{
${ }^{7}$ En realidad, ningún verdadero renacimiento funciona como una pura y simple copia.

${ }^{8}$ J. M. Keynes, Teoría General de la ocupación, el interés y el dinero, p. 285, FCE, México, 1974.

${ }^{9}$ Publicado en 1937, en Econométrica.

${ }^{10} \mathrm{Cf}$. A. Hansen, Guía de Keynes, FCE, México, 1983. La $1^{\text {a } e d i c i o ́ n, ~ e n ~ i n g l e ́ s, ~ d a t a ~ d e ~} 1953$.

${ }^{11}$ Basil J. Moore, Horizontalists and Verticalists. The macroeconomics of credit money, p. 366. Cambridge University Press, 1988.
} 
post-keynesiana, en sí misma correcta, desemboca en una noción metafísica y equívoca del tiempo histórico. La incertidumbre (como expectativas no probabilizadas) se entiende en un sentido completamente ahistórico pues no se pretende, ni remotamente, anclarla y determinarla en condiciones socio-históricas precisas (vg. en la economía mercantil). Es decir, el reclamo por un tiempo histórico termina por remitirnos a una dimensión temporal ahistórica. Otro punto más que discutible e íntimamente ligado al anterior es la forma en que se rescata el viejo argumento de Hume en contra del empirismo ingenuo. Al rechazar la denominada "hipótesis ergódica" y aceptar la "histéresis", se lo hace en términos que más bien se asemejan al rechazo de la posibilidad de un manejo científico de los asuntos económicos. ${ }^{12}$ Un segundo y decisivo punto subrayado por los post-keynesianos se refiere a los salarios y al nivel de precios. Como apunta J. Robinson, no hay lugar para que "la productividad marginal determine las tasas de los salarios reales, ni a que la cantidad de dinero determine los precios (...) $\mathrm{El}$ aspecto más importante de la revolución keynesiana fue el reconocimiento de que, en una moderna economía industrial, el nivel general de precios en cualquier fase del desarrollo técnico depende, principalmente, del nivel de las tasas de salario-dinero. ${ }^{13}$

Hasta el boom Kennedy-Johnson y en general hasta fines de los sesentas, el predominio del paradigma keynesiano (el Keynes neoclásico de la síntesis) fue prácticamente incontrarrestable. En la enseñanza universitaria $v g$., los manuales más utilizados de macroeconomía eran sorprendentemente homogéneos en cuanto a sus contenidos básicos. El profesor, al elegir tal o cual texto tenía que preocuparse casi exclusivamente de sus virtudes pedagógicas pues el modelo teórico básico se daba por descontado. En el diseño de las políticas económicas, también se llegó a grandes coincidencias y consensos. No obstante, ya promediando la década los sesenta se comienzan a observar fuertes desafíos. Por la izquierda y en evidente concomitancia con los movimientos de rebeldía de los años sesentas (el cheguevarismo, la Revolución Cultural China, el mayo francés, el otoño caliente italiano, la primavera de Praga), se observa el renacimiento de Ricardo (por la vía de Sraffa) y de la economía marxista. Con ello, se reactualizan categorías de tanta estirpe como excedente, explotación, valor, acumulación, gastos improductivos. Además, los mismos fundamentos de la teoría neoclásica del valor y la distribución son sometidos a una crítica devastadora. De la cual, por lo

${ }^{12}$ Cf. B. Moore, op. cit., pp. 368-371.

${ }^{13}$ Joan Robinson y Eatwell, op. cit., p. 72. 
demás, el establecimiento universitario estadounidense hasta hoy casi no se da por enterado. ${ }^{14}$

Por la derecha, el monetarismo de Friedman avanza más. La crisis y la estanflación de los setenta marcaron un hito decisivo. A fines de la década, Tobin escribe: "vivimos tiempos difíciles para la macroeconomía, tanto teórica como aplicada a la política económica. Nuestra profesión está profundamente dividida en puntos esenciales: sobre cómo hacer un modelo de la estructura de nuestras economías así como sobre qué políticas gubernamentales pueden mejorar sus rendimientos. Desde mediados de los sesenta han decaído el grado de consenso sobre la 'síntesis neoclásica' postkeynesiana junto con la confianza en el potencial estabilizador de una activa intervención fiscal y monetaria, en algún momento presidido por la síntesis neoclásica”. ${ }^{15}$ Otro autor de no menos prestigio -John R. Hicks- sostiene que el boom económico se asociaba a las políticas keynesianas y ello les otorgaba un evidente prestigio. Pero cuando surge el estancamiento y la inflación, ese prestigio se deteriora: “ no es de ningún modo sorprendente-por el contrario es perfectamente natural- que si las doctrinas de Keynes dan en un momento, o parecen dar, resultados menos satisfactorios, sean puestas en tela de juicio, así como sus bases intelectuales". ${ }^{16}$

A primera vista, se arriba a una típica crisis teórica. Y en términos casi apriorísticos se podría sostener: i) las estructuras económicas sufren mutaciones importantes; ii) ello, provoca el desajuste teórico; iii) se necesitaba, por ende, un recambio teórico. Todo, por lo tanto, muy normal, muy de acuerdo con la lógica de las crisis teóricas y del progreso científico según la han descrito autores inclusive tan disímiles como Popper, Kuhn, Lakatos y otros.

Por lo menos, ésa era la apariencia. El recambio teórico sí se dio, pero lo que es -digámoslo así- "curioso”, es que el recambio asume la forma de una recuperación del pasado. Lo que Alvin Hansen daba por totalmente muerto, resucita con fuerza increíble.

\footnotetext{
${ }^{14}$ Ferguson, alude a la crítica y señala: "su validez es incuestionable, pero su importancia es empírica o econométrica, y depende de la posibilidad de sustituciones que haya en el sistema. Hasta que los econometristas nos den la respuesta, confiar en la teoría neoclásica es cuestión de fe (¡Lutero ad portas! J. V. F.). Personalmente tengo fe; pero en la actualidad lo mejor que puedo hacer, para convencer a otros, es invocar el peso de la autoridad de Samuelson...”. Cf. C. E. Ferguson, Teoría neoclásica de la producción y la distribución, Prólogo, p. 8; Trillas, México, 1985. Como se ve, los criterios de Ferguson -la fe, la autoridad- son ultra "serios" y "científicos".

${ }^{15}$ James Tobin, "Una valoración de la actual contra-revolución monetarista"; en Información Comercial Española, diciembre, 1981.

${ }^{16}$ John R. Hicks, La crisis de la economía keynesiana, p. 11, Barcelona, 1976.
} 
En la última parte de los setenta, emerge y se difunde con inusitada rapidez una nueva corriente, aquélla que Tobin denominara "monetarismo II"17 y que es más conocida como "nueva macroeconomía clásica" o escuela de las expectativas racionales. Al comenzar los ochenta, en Estados Unidos, esta corriente parece iniciar una marcha triunfal incontenible.

Se ha escrito, por ejemplo, que en torno a 1980, ningún académico dedicado a la macroeconomía menor de 40 años, en Estados Unidos, se declaraba keynesiano ${ }^{18}$. Es decir, todos los académicos jóvenes reconocían filas en los grupos neoclásicos más extremistas, en la denominada "nueva macroeconomía clásica" de las expectativas racionales.

Con toda justicia, Friedman, Brunner, Meltzer, Sargent, Lucas y demás, podrían recordar aquello de "los muertos que vos has matado, gozan de buena salud”. Y adviértase la impresionante similitud de las apreciaciones: hace unos 60 años, para celebrar el advenimiento de la era keynesiana que además sepultaba a la ortodoxia neoclásica; luego, digamos antes de ayer (hacia los ochenta del siglo xx) se celebran también decesos y nacimientos. Los protagonistas son idénticos pero los papeles han cambiado. Los keynesianos se mueren, los neoclásicos resucitan. ¿Por qué el repunte conservador? ¿Por qué esta especie de ciclos de retorno casi eternos? Y como hacia fines del siglo (o inicios del siglo xxI, máxime después de la crisis de orden estructural que viene sufriendo el capitalismo central) muy probablemente estaremos asistiendo a la decadencia de la escuela de Lucas, Barro et al y al auge de los "nuevos keynesianos", ¿acaso no sería necesario preguntarnos sobre el por qué de estos movimientos ondulatorios, no muy propios de una disciplina que se pretende ciencia? ${ }^{19}$

Surgen aquí problemas muy delicados y que nos exigen una mínima referencia y atención.

Primero, tenemos un problema lógico. En los años treinta, la teoría A fue criticada y reemplazada por la teoría B. ¿Por qué? Porque A respondía a la realidad T, ya pretérita; y no a la realidad vigente, del tipo Y. En los setenta y ochenta, la realidad $Y$ se transforma en la realidad $Z$ y, por ello, entra en crisis la teoría B. La teoría que emerge, en correspondencia con $Z$ es la del tipo A.

${ }^{17}$ Cf. James Tobin, Reflexiones sur le theorie macroeconomique contemporaine, Paris, 1983.

18 Alan Blinder, "The Fall and Rise of Keynesian Economics"; Economic Record, dec. 1988.

${ }^{19}$ En realidad, esta decadencia de los "nuevos neoclásicos" ya parece haber comenzado. Según Dornbusch, "la nueva economía clásica está pasando de moda". Ver su prólogo a J. C. de Pablo, Macroeconomía, FCE, B. Aires, 1991. 
Tenemos entonces, las siguientes relaciones:

- En el plano real: $\mathrm{T} \neq \mathrm{Y} ; \mathrm{Y} \neq Z ; Z \neq \mathrm{T}$

- En el plano teórico: $A \neq B ; A=A$

- En el plano epistemológico: $\mathrm{A} / \mathrm{T}=\mathrm{B} / \mathrm{Y}=\mathrm{A} / \mathrm{Z}$

O sea, deberíamos concluir que $Z=T$, lo que claramente infringe las premisas y es absurdo. El asunto no es lógico, pero sí real.

$\mathrm{El}$ problema, nos lleva a plantear otro. Cuando asumimos las relaciones de correspondencia epistemológica entre teorías y realidades, estamos manejando un supuesto sencillo y propio de la práctica científica: las teorías deben reflejar lo material-objetivo y cuando dejan de hacerlo (son "falsadas" de acuerdo al criterio popperiano) deben ser reemplazadas por otras. Pero, ¿qué puede significar que el reemplazo no tenga lugar? Este sería el segundo problema a subrayar. Desde ya, se puede advertir sobre algo: el no reemplazo significa que los ciclos de dominación teórica no responden, al menos completamente, a la dialéctica del desarrollo que exige la ciencia $(i$. e. el apegarse a la verdad) sino, al menos en parte, a otros factores o fuerzas motrices. O sea, con la teorización económica no se persigue exclusivamente un reflejo verdadero de la materia. También, se persigue algo más y que no provoca los mismos resultados (al menos en todos los casos) que la persecución de la verdad.

\section{Multiplicidad de paradigmas y corrientes}

Uno de los aspectos más llamativos de la actual situación de la teoría económica radica en la gran variedad de escuelas y corrientes que en su interior pululan. Y sin pretender unanimidades y uniformidades que en ninguna ciencia existen, pareciera que esta situación no es muy propia de una disciplina que aspira a ser reconocida como una ciencia cabal.

Para el caso, podemos recordar un comentario de Kant, el gran pensador alemán. Refiriéndose a la filosofía, Kant señalaba que "parece casi digno de risa que, mientras todas las ciencias progresan incesantemente, la que se tiene por la sabiduría misma, cuyo oráculo todos los hombres consultan, dé vueltas siempre en la misma dirección, sin poder avanzar un poco". ${ }^{20}$

Un comentarista de Kant, a su vez, apunta que "los matemáticos, los físicos, los químicos, no vuelven cada uno a poner en cuestión la totalidad ${ }^{20}$ E. Kant, Prolegómenos a toda metafísica del porvenir, p. 21; edit. Porrúa, México, 1978. 
de su ciencia, sino que recogen los progresos de sus antecesores y añaden nuevas proposiciones verdaderas a las ya admitidas como tales. Pero en la filosofia, nada queda firme. Cada pensador destruye todo lo hecho antes de él y construye de nuevo un edificio", de aquí que "la historia de la filosofía no es la historia de una ciencia, sino la historia de múltiples sistemas, deshechos apenas terminados y enseguida sustituidos por otros, que corren pronto la misma suerte". ${ }^{21}$

La economía, por cierto, no es la filosofía, pero el panorama que describen Kant y García Morente guarda desazonantes puntos de similitud con el paisaje que hoy podemos observar en nuestra disciplina.

Demos un vistazo, breve y a vuelo de pájaro. Marx nunca ha desaparecido de la escena. Luego de Sraffa, el renacimiento de Ricardo es notorio. Y están los neoclásicos, los descendientes de Menger, Walras y Marshall. Y los keynesianos de toda laya.

En la derecha del espectro no hay una sino varias corrientes: a) la moderna escuela austriaca, la que viene desde Karl Menger y Eugen BöhmBawerk. La impulsada en las últimas décadas por Ludwig von Mises y Friedrich von Hayek; b) la "nueva macroeconomía clásica" o escuela de las expectativas racionales, encabezada por autores como R. Lucas, Th. Sargent y Robert Barro; $c$ ) el monetarismo más tradicional, el de K. Brunner y Milton Friedman, el que James Tobin ha denominado "monetarismo I" (siendo el II, el de Lucas); d) la corriente ofertista, citada y publicada por algunos, pero que pensamos no alcanza la categoría mínima a exigir como para catalogarla corriente o escuela de pensamiento; e) actuando como sustrato último de b), c) y d), el modelo de equilibrio general walrasiano, desarrollado contemporáneamente por Arrow, Debreu y otros. Todas estas corrientes se tipifican por su contenido ultra-conservador, su creencia en la estabilidad esencial del capitalismo privado, en el carácter auto-regulador (homeostático) del mercado, y en su duro rechazo al regulacionismo estatal.

En el centro del espectro, la variedad no es menor. Se podría sostener que el Keynes de la Teoría General funciona aquí como tronco básico o matriz primigenia, pero grande es el forcejo en torno a cuál es la interpretación más adecuada del esquema enarbolado por el gran economista inglés. Podríamos quizá distinguir las siguientes grandes corrientes: a) la "síntesis neoclásica", es decir el Keynes de la IS/LM de Hicks y Hansen, asociado a autores como Samuelson, Tobin y Modigliani. Es el Keynes asimilado al esquema neoclásico de equilibrio general, lo cual -según muchos autores-ha desvirtuado

${ }^{21}$ M. García Morente, La filosofía de Kant, p. 19; España-Calpe, Madrid, 1975. 
su mensaje original y, por eso, tales autores han llegado a hablar de "keynesianismo bastardo"22; b) la "nueva economía keynesiana", término que ha manejado Robert J. Gordon ${ }^{23}$ para referirse al trabajo que en polémica (y en parte asimilación) con la escuela de expectativas racionales, han efectuado algunos nuevos jóvenes keynesianos. En sus palabras, ha habido en los ochenta, "un chorro de investigaciones que al interior de la tradición keynesiana han buscado construir los fundamentos microeconómicos de la fijeza o 'viscosidad' de los salarios y precios". ${ }^{24}$ En realidad, si bien se piensa, los "nuevos clásicos" (que son mas bien, nuevos neo-clásicos) han rescatado y extendido los límites de la microeconomía neoclásica o tradicional lo que, al final de cuentas, los ha llevado a disolver lisamente la macroeconomía (esto, equivaldría a un triunfo del individualismo o atomismo metodológico). Entretanto, los "nuevos keynesianos" (Gordon, S. Fisher, Taylor, H. Grossman, et al buscan acomodar la microeconomía a las realidades del fin de siglo -precios pegajosos, estructuras oligopólicas-y preservar así el núcleo básico de la macroeconomía llamada keynesiana; c) existe otra corriente, denominada a veces neo-keynesiana, donde se ubican autores como: Clower, Leijonhufvud, Stiglitz, los franceses Malinvaud y J. P. Benassy, el japonés Negishi y otros. Estos autores buscan desarrollar un enfoque de equilibrio general no walrasiano que enfatiza los ajustes de cantidades y acepta, por ello, la existencia de precios relativamente fijos o que reaccionan con gran lentitud. ${ }^{25}$ Entre esta corriente y la antes mencionada de los "nuevos keynesianos" hay muchos y obvios puntos de contacto y las fronteras -de haberlas- son bastante difusas. Entre ambas corrientes se puede pronosticar un proceso de convergencia e integración más o menos fuerte. Y no sería raro que llegara a ocupar una posición dominante (en reemplazo de la corriente de expectativas racionales) en el establecimiento académico; $d$ ) la escuela de los post-keynesianos, donde encontramos a autores como Alfred Eichner, Paul Davidson, Sydney Weintraub, Hyman Minsky y otros. En esta escuela, a veces se agrupan también a autores como: Kalecki, Steindl y Sylos Labini, los cuales representan una variante quizá no menor respecto a los antes

${ }^{22}$ Joan Robinson, What has become of the Keynesian Revolution? Challenge; enero-febrero de 1974.

${ }^{23}$ Robert J. Gordon, “What Is New Keynesian Economics?”, en Journal of Economic Literature, vol. xxviII, September, 1990.

${ }^{24}$ Op. cit. p. 1115.

${ }^{25}$ Por ello, algunos autores -como Negishi- comienzan a redescubrir a Karl Menger, neoclásico fundador que se interesaba más que en los precios de equilibrio, en los procesos, para nada instantáneos, que conducían al estado de "santidad neoclásica". Por esta vía, se producen también encuentros con la escuela austriaca, en algún grado. 
mencionados. El último Kaldor también se asocia a esta corriente. Y, por cierto, en quien recae el papel de gran líder intelectual de la corriente no es otra que la ya legendaria Joan Robinson. Usando términos no académicos, puede afirmarse que la corriente post-keynesiana nos muestra un impresionante elenco de grandes estrellas del firmamento económico.

Según Ocampo, un rasgo común del post-keynesianismo "es el intento de rescatar y desarrollar elementos de la revolución keynesiana (entre ellos los aportes del economista polaco M. Kalecki) que quedaron relativa o enteramente olvidados en la "gran síntesis". ${ }^{26}$ Este mismo autor anota que "el problema básico de la teoría keynesiana es la ausencia de un análisis de la empresa, los precios y la distribución firmemente sustentada en los conceptos de incertidumbre y demanda efectiva. La ausencia de este análisis condujo a los seguidores de Keynes en dos direcciones opuestas. Por una parte, conceptos derivados de la teoría neoclásica se intentaron compaginar con el análisis keynesiano del corto plazo en la 'gran síntesis'. Por otra, los autores post-keynesianos ampliaron los elementos de la ruptura con el neoclasicismo, extendiendo los conceptos de incertidumbre y demanda efectiva en estas esferas". ${ }^{27}$

Hacia la izquierda del espectro tampoco se puede hablar de un paradigma homogéneo. Cierto es que así como en el centro la figura de Keynes funciona como un foco de irradiación o imán casi irresistible, en el polo de la izquierda Marx juega un papel bastante similar. Difícilmente podemos hablar de corrientes teóricas que, de una u otra manera, no respondan en mayor o menor grado a su poderoso influjo.

No obstante, en la izquierda no todo es sensu-stricto marxista. Además, al interior del marxismo coexisten (no siempre en términos pacíficos) corrientes a veces muy disímiles.

Limitándonos a una muy tosca apreciación podríamos señalar las siguientes grandes corrientes.

a) El neo-ricardianismo. Su origen, muy nítido y claro, reside en el famoso texto de Piero Sraffa, "Producción de mercancías por medio de mercancías”. A esta corriente se pueden adscribir autores como P. Garegnani, G. Roncaglia, Gilbert Abraham-Foris I. Steedman, G. Hogdson $^{28}$ y otros. Son autores que se diferencian de la escuela marxista en tanto tienden a sustituir el valor por la mercancía estándar

26 J. A. Ocampo, Economía poskeynesiana, p. 9, FCE, México, 1988.

28 Este último ha derivado al llamado "neo-institucionalismo". 
compuesta de Sraffa y, de hecho, piensan que el manejo de la categoría valor constituye un rodeo innecesario.

b) El marxismo analitico. Roemer es su representante más destacado. Tienen muchos puntos de contacto con el neo-ricardianismo y a veces se ha llegado a calificar a esta corriente como "marxismo walrasiano". Se trata, sin duda, de un proyecto en expansión y cuyo programa de investigación sobrepasa los límites de la pura economía. Aunque, muy probablemente, en épocas de crisis de orden mayor (como la que transcurre del 2007 a la fecha) se debilite su impulso.

c) La escuela de la estructura social de la acumulación. Encontramos aquí, a autores como Bowles, Gintis, Edwards, Reich, Gordon, Weisskopf y otros. Aparte de Marx, reconocen filiaciones teóricas en Keynes, en Shumpeter y -algo- en Sraffa. Constituyen el núcleo central de la denominada "economía radical".

d) La escuela de la regulación. Corriente francesa escindida del marxismo soviético donde encontramos a autores como: Lipietz, Boyer y otros. Aparte de Marx, son muy cercanos a Kalecki y Steindl.

Y con seguridad pueden converger con la corriente antes mencionada.

e) El luxemburguismo. Escuela marxista que enfatiza los problemas que derivan del subconsumo y de una demanda efectiva insuficiente. Aparte de Rosa Luxemburgo, se pueden asociar a esta corriente a autores como T. Kovalicki (polaco), Henri Denis (francés) y, en algún sentido no muy preciso, a Paul Baran, Paul Sweezy, Harry Magdoff y Howard Sherman.

f) El trotsquismo. En economía, gira en torno a la obra de Ernest Mandel, pero sus contornos (en teoría económica) no son precisos o muy diferenciados.

g) El marxismo soviético. Para muchos y durante largos años, fue el sinónimo de la ortodoxia marxista. Responde a una visión hegeliana derechizante y frente a sus virtudes sistemáticas y globalizantes se les suele oponer su debilidad empírica y operacional. Aparte de que su tendencia apologética lo conduce, en no pocas ocasiones, a incurrir en simplificaciones burdas, faltas muy elementales a la lógica. En la actualidad, por el derrumbe de la Unión Soviética, muy debilitado o, más bien, en vías de desaparición.

Para no abusar, cortamos aquí la lista, aunque bien se podría alargar. Asimismo debemos señalar que: i) no hemos aclarado los criterios de demar- 
cación; ii) entre las diversas corrientes mencionadas, se dan superposiciones y "tierras de nadie y en disputa"; iii) de seguro, se podría decir que tal o cual autor debería clasificarse en otro renglón; iv). En breve, más que clasificaciones precisas, nos interesaba llamar la atención sobre el número, impresionantemente elevado, de escuelas y corrientes teóricas que hoy pululan en el mundo académico de la economía. ¿Qué es lo que posibilita esta situación tan anómala para una ciencia? Sin pretender entrar ahora a ensayar una explicación, hay algo que evidentemente tiene lugar: los criterios de verificación propios de las ciencias "duras", en nuestra disciplina no se aplican y si se aplican, sus conclusiones no se respetan. Dicho de otro modo: en ocasiones dilucidar si tal o cual hipótesis es falsa o verdadera, resulta extremadamente difícil cuando no imposible. Lo cual, tiene que ver no sólo con las dificultades que impone la naturaleza del objeto sino que, también, con la forma metafísica con que se plantean los enunciados o proposiciones teóricas. En segundo lugar, debemos reconocer un fenómeno más grave: la especial capacidad (¿dureza?, ¿deshonestidad?) con que casi todas las corrientes se las arreglan para ignorar o rechazar las evidencias empíricas que las falsean y rechazan.

\section{Ambigüedades metodológicas}

En el campo neoclásico podemos observar una situación bastante contradictoria y curiosa. Al menos en el mundo anglosajón, casi todos los economistas declaran su adhesión a los criterios epistemológicos desarrollados por los hombres del Círculo de Viena (Schlick, Carnap, Wittgenstein y otros) o por Karl Popper. De hecho -valga la acotación al pasar- suelen confundir las posturas de Popper con las del círculo.

La influencia del positivismo lógico en los economistas anglosajones tiene orígenes casi accidentales. La citada escuela filosófica florece en la Austria de entreguerras, previa al advenimiento del fascismo. Sus raíces, se sitúan incluso antes de la $1^{\text {a }}$ Guerra Mundial, en esa Viena y centro-Europea que llegó a ser una fiesta del espíritu. Y si Moritz Schlick -tal vez la cabeza más brillante del Círculo- fue asesinado por un estudiante fascista, los otros miembros se vieron obligados a emigrar ante el peligro hitleriano. Wittgenstein llegó a Cambridge donde cultivó las amistades de Keynes y Piero Sraffa. Otros, como Rudolf Carnap, emigraron a Estados Unidos. En este país, hasta el primer tercio del siglo xx, el cultivo de la filosofía era francamente mediocre y los hombres del círculo, alemanes y europeos, muy pronto se 
apoderaron de la dirección de muchos departamentos de filosofía, como vg. en Harvard, en Chicago y otras grandes e influyentes Universidades. Y por esta vía, influyeron en las escuelas de economía, en las posiciones epistemológicas que allí se comenzaron a manejar.

En Estados Unidos, antes del arribo del neo-positivismo, las posturas metodológicas esgrimidas por los economistas más orientados al trabajo teórico, sugestivamente se alineaban principalmente en las filas del apriorismo kantiano más que en el pragmatismo utilitario de un William James. Este, por ejemplo, es característicamente el caso de Franck H. Knight, autor que desarrolla ásperas polémicas con el positivismo. En sus palabras, "las proposiciones y definiciones fundamentales de la teoría económica no son ni observables ni inferidas de la observación". ${ }^{29}$ Asimismo sostiene que la teoría económica, por su método, es una ciencia "similar a la geometría". ${ }^{30}$ La postura de Knight es similar a la de autores como el inglés Lionel Robbins $^{31}$ y los austriacos Ludwig von Mises y Friedrich von Hayek, para quienes las proposiciones y enunciados centrales de la teoría económica poseen una naturaleza que es similar a los juicios a priori y sintéticos desarrollados por Kant. Según von Mises, la economía teórica opera en el espacio del "entendimiento puro" y sus "teoremas concretos no son susceptibles de verificación o falsación alguna en el terreno de la experiencia... la medida última de la corrección o falta de ella de un teorema económico es únicamente la razón, sin ayuda de la experiencia”. ${ }^{32}$ En general, esta postura metodológica coincide con la manejada por la denominada escuela austriaca, aquélla rama de la visión neoclásica que se origina a partir de Karl Menger. Este, distingue las "leyes exactas" de las "leyes empíricas", las que se obtienen por inducción y nos proporcionan una comprensión insuficiente de los fenómenos, permiten una predicción insegura y no nos otorgan una garantía absoluta y a priori de su validez. La economía teórica -según Menger- debe buscar "leyes exactas", las que dados ciertos axiomas se obtienen deductivamente y cuya validez no se corrobora con test empíricos. ${ }^{33}$ Dicho de otro modo, terminamos por arribar a las "verdades de razón” manejadas por Leibniz.

\footnotetext{
${ }^{29}$ F. H. Knight, On the History and Method of Economics, p. 154, The University of Chicago Press, Chicago, 1966.

${ }^{30}$ Ibíd., p. 168.

${ }^{31}$ Ver su muy influyente Ensayo sobre la naturaleza y significación de la ciencia económica, FCE, México, 1954.

${ }^{32}$ Ludwig von Mises, Human Action. A Treatise on Economics, p. 858, London, 1949.

${ }^{33}$ Ver Karl Menger, Investigations into the Methods of the Social Sciences with Special reference to economics, en especial, los capítulos 3, 4 y 5 del libro I; New York University Press, N. York, 1985.
} 
Junto al apriorismo sintético, en Menger destaca su rechazo a la noción ultra-empirista de una realidad plana y su correlato: el desarrollo de una ciencia puramente descriptiva. En su opinión, la ciencia debe identificar la naturaleza esencial de los fenómenos y, por esta vía, llegar a comprenderlos. Es decir, saber su porqué o "la razón de su existencia". ${ }^{34} \mathrm{Si}$ evitamos cierto componente subjetivo -como la introspección psicológica- que a veces se incluye en la "verstehen" (comprensión) gnoseológica, ${ }^{35}$ el aspecto "esencialista" de la visión de Menger constituye un buen antídoto de aquellas concepciones instrumentalistas que creen que la ciencia no es más que una caja negra. ${ }^{36}$

Ahora bien, según ya hemos advertido, en la segunda mitad de este siglo, el grueso de los economistas se declaran, en cuestiones de método, partidarios del neopositivismo. Al decir de Paul Samuelson, "en relación con las exageradas pretensiones que solían sostenerse en cuanto al poder de la deducción y el razonamiento apriorístico en economía -hechas por los escritores clásicos, por Karl Menger, por el Lionel Robbins de 1932... por los discípulos de Frank Knight y por Ludwig von Mises-, yo tiemblo por la reputación de mi disciplina". ${ }^{37}$ Como vemos, ahora se cree que la "reputación" viene dada por el rechazo al antiguo apriorismo.

En su obra capital, Los fundamentos del análisis económico, Samuelson plantea un abrupto rechazo a los enfoques aprioristas, un claro malestar respecto al "estatuto científico" de la argumentación neoclásica y, asimismo, señala la necesidad de respetar los cánones metodológicos del neopositivismo. En sus palabras, "sólo la más pequeña fracción de los escritos económicos, teoréticos y aplicados, se ha preocupado de la derivación de teoremas operacionalmente significativos". ${ }^{38}$ Esto, a su vez, se debería a la errónea preconcepción metodológica según la cual "las leyes económicas son deducidas de supuestos a priori que poseerian rigor y validez independientemente de cualesquier comportamiento humano". ${ }^{39}$ A quien haya leído los Foundations estas declaraciones iniciales en contra del apriorismo no

\footnotetext{
${ }^{34}$ Op. cit., p. 43.

35 Patente en autores como Rickert, Windelband, Dilthey y otros filósofos de las "ciencias del espíritu”. De paso, digamos que la influencia de esta corriente es muy nítida en J. Schumpeter. ${ }^{36}$ Caso de M. Friedman.

${ }^{37}$ P. Samuelson, según M. Blaug, op. cit., p. 113.

${ }^{38}$ Paul A. Samuelson, "Foundations of Economic Analysis", p. 3, Cambridge, Harvard University Press, 1971. Por operacionalmente significativos Samuelson entiende los enunciados con "significación cognitiva", es decir, aquéllos que necesitan de la contrastación empírica para decidir sus valores veritativos.

${ }^{39}$ Ibíd., p. 3.
} 
pueden sino resultar sorprendentes: pocos libros más apriorísticos que los Foundations. Al cabo del tiempo, el mismo Samuelson ha reconocido que en ese libro “...no me apegué demasiado consistentemente a mi programa de derivar teoremas operacionalmente significativos; de otro modo, tópicos como la economía del bienestar y la economía dinámica podrían haber sido excluidos". ${ }^{40}$ Esta situación viene resultando muy típica de la economía convencional: se predica una cosa y se practica otra. El mismo Samuelson, por ejemplo, se pronuncia muy elocuentemente a favor del principio de la inducción empírica: "toda ciencia está firmemente basada en la inducción a partir de la observación de los hechos empíricos". ${ }^{41}$ Pero, al mismo tiempo y sin pestañar, nos dice que el equilibrio general walrasiano constituye "la cima de la economía neoclásica" ${ }^{42}$ y bien sabemos que en materias de macroeconomía su principal esfuerzo se orientó a la integración del esquema de Keynes en un modelo de equilibrio general. Y, por cierto, pretender que el modelo walrasiano constituye una "generalización empírica" resulta una descomunal tomadura de pelo. ${ }^{43}$

Como se sabe, una de las motivaciones que tuvo Walras para desarrollar su obra fue su rechazo a las prédicas y doctrinas de Proudhon. Este aspiraba a un modelo de sociedad muy confuso -medio capitalista, medio socialista o, si se quiere, una especie de economía mercantil simple e igualitaria, con muchos puntos de contacto con el ideal económico de Rousseau- y, de modo fundamental, esgrimía una feroz crítica a las instituciones capitalistas y a sus consecuencias de miseria e injusticia. A Walras, las prédicas de Proudhon le causaban inquietud, malestar y temor. Amén de peligrosas, le parecían irracionales, ajenas al "élan" ilustrado que había heredado -según propia confesión- de los revolucionarios franceses. ${ }^{44} \mathrm{Su}$ afán, entonces, fue construir un discurso que demostrara -más que "more geométrico", more mecánica-física- con absoluta claridad, rigor y exactitud, las ventajas del mercado y el régimen de propiedad vigente. Dicho de otro modo, al revés de lo planteado por Proudhon -que, entre otras tesis rimbombantes, sostenía que "la propiedad es un robo"- para Walras, la razón y la racionalidad

${ }^{40}$ P. A. Samuelson, "Foreword to the Chinese translation of Foundations of Economic Analysis"; en The Collected Scientific Papers of P. A. Samuelson, vol. II, p. 691, The mit Press, Cambridge, Mass., 1977.

${ }^{41}$ P. A. Samuelson, “Economic Theory and Mathematics”; en The Collected...”, op. cit., pp. 1752. 42 Ibíd., p. 1756.

${ }^{43}$ El mismo Walras se declaraba kantiano: "absorbió la influencia de la filosofía kantiana a través de la popularización efectuada por Víctor Cousin”, $C f$. B. Ingrao y G. Israel: The Invisible Hand, Economic Equilibrium in the History of Science, p. 97; MIT Press, Cambriedge, Mass., 1990.

${ }^{44}$ En todo caso, del ala derecha de la revolución. 
no podían sino alinearse con la sociedad actual. Además, con una actitud también en este plano muy kantiana, terminaba por identificar los principios de la razón, con el reino del imperativo moral, la justicia y la libertad.

En breve, tendríamos que el modelo de Walras; i) respondería a los principios del apriorismo sintético de Kant; ii) tendría una orientación más formativa que positiva. Pero en esto no se agotan las dudas que suscita el modelo.

En la obra de Walras, hay preguntas que no resuelve la igualdad de ecuaciones e incógnitas. Por ejemplo: ¿existe una solución económicamente significativa? ¿Tal solución es única? ¿Es estable? Autores como H. Wald, K. Arrow $^{45}$ y G. Debreu ${ }^{46}$ se han dedicado a analizar y resolver esos problemas. En sus afanes, han recurrido al método axiomático, un método cada vez más utilizado en las ciencias más maduras (físico-matemáticas, química) y que posee obvias virtudes de rigor, claridad y exactitud. ${ }^{47} \mathrm{El}$ afán, por lo mismo, parece loable pero hay que advertir rápidamente: en la teoría económica convencional, el método axiomático se inserta de un modo bastante diferente al que se observa en los corpus científicos más establecidos y reconocidos. En la teoría económica neoclásica las deducciones que posibilita la axiomatización muy a menudo arriban a: i) conclusiones que no pueden ser verificadas (i. e., sometidas al test empírico) y son, por ello, simples enunciados metafísicos; ii) conclusiones que empíricamente rechazadas (falsadas según la expresión popperiana), se mantienen con tremenda pertinacia.

En el caso de los modelos walrasianos, la axiomatización se coloca al servicio de una construcción apologética cuya sustancia (no así su forma) es sumamente vulgar: se trata de "probar" las bondades del régimen capitalista, de "probar" su capacidad para maximizar el bienestar social. El propósito primigenio de Walras se conserva. Sólo se cambian los métodos y las formas (ahora ultrasofisticadas) de la demostración buscada. La misma secuencia que sigue la construcción de los modelos walrasianos contemporáneos es más que sugerente: primero se eligen las conclusiones que se desea "probar" y luego se infieren los axiomas adecuados. Es decir, los que permiten arribar a las conclusiones previamente elegidas. Al decir del economista francés Bernard Guerrien, los neoclásicos "han adoptado una problemática de axiomatización en la cual el problema central llega a ser ¿qué hipótesis deben efectuarse para demostrar que las normas del mercado conducen a un ópti-

${ }_{45}$ Keneth Arrow y F. H. Hahn, Análisis general competitivo, FCE, México, 1977.

${ }^{46}$ Gerard Debreu, Teoría del valor: un análisis axiomático del equilibrio económico, A. Bosch editor, Barcelona, 1973.

${ }^{47}$ No así de completitud, según lo demostró Gódel con su famoso teorema. 
mo? Dicho de otro modo, no se trata de partir de hipótesis para arribar a un resultado sino de partir del resultado para determinar en qué condiciones ( $i$. e., con qué hipótesis) aquello puede ser logrado." 48 Con lo cual, se asumen hipótesis iniciales o supuestos que resultan hasta delirantes.

Hay economistas que han expresado un abrupto rechazo a los esquemas walrasianos. Keynes, por ejemplo, señalaba que "tanto la teoría de Walras como todas las otras que tienen los mismos lineamientos, ison puros disparates!". ${ }^{49}$ N. Kaldor no es menos tajante y escribe que "los hábitos de pensamiento engendrados por la teoría económica del equilibrio han llegado a ser el principal obstáculo para el desarrollo de la economía como ciencia". ${ }^{50}$ Alfred Eichner, el gran impulsor de la escuela post-keynesiana, sostiene que la economía "no es todavía una ciencia" y que es el corpus teórico neoclásico el gran responsable de esta situación desmedrada. ${ }^{51}$

En su versión walrasiana -que es de lejos dominante- la teoría neoclásica tiene muy pocos puntos de contacto con las realidades económicas contemporáneas. Según Keynes, "sus enseñanzas engañan y son desastrosas si intentamos aplicarlas a los hechos reales". ${ }^{52}$ No obstante, esos esquemas no son fantasmas que se limitan a vagar por el limbo académico. Nada de eso, el esquema se materializa con especial fuerza en los periodos de crisis y suele pasar a orientar las políticas de ajuste que en tales momentos se implementan. La llamada Ley de Walras y las restricciones presupuestarias que se le suponen a cada sector, plantea que a cada escala global no puede existir ningún tipo de demanda excedentaria. Por ende, si en (n-1) mercados se observa una demanda excedentaria, en el mercado n-ésimo forzosamente existirá una oferta excesiva de igual magnitud. Por ejemplo, supongamos que en el mercado de dinero la oferta supera a la demanda: hay exceso de saldos monetarios. La contraparte será, en este caso, una oferta deficitaria en el mercado de bienes. O bien, si en éste suponemos equilibrio habrá un saldo externo negativo (las importaciones superan a las exportaciones). O sea, la oferta de divisas será deficitaria. Si esto, vg., lo aplicamos a América Latina donde la crisis de balance de pagos suelen ser recurrentes, la "receta" a deducir es nítida: restringir la oferta monetaria y reprimir el nivel de la demanda global. Para el modelo neoclásico, ésas medidas sólo deberían afectar

\footnotetext{
${ }^{48}$ Bernard Guerrien, L'economie neo-classique, p. 10; edic. La Découverte, Paris, 1989.

${ }^{49}$ J. M. Keynes, carta a J. R. Hicks (9/12/1934).

${ }^{50}$ N. Kaldor, Further Essays on Economic Theory, p. 176, Duckworth, 1978.

${ }^{51} \mathrm{Cf}$. Alfred Eichner, Why Economics is not a Science, Aparece con algunas correcciones y agregados, como cap. 15 de The Macrodynamics of Advanced Market Economies, M. E. Sharpe, N.yor \& London, 1991.

${ }^{52}$ J. M. Keynes, Teoría General, p. 15. edición citada.
} 
al nivel de precios, corregir el déficit externo y dejar prácticamente intocado al sector real (enfoque dicotómico y tesis de la neutralidad del dinero). Lo cierto es que, de acuerdo a la evidencia empírica acumulada, los resultados son muy diferentes y confirman la predicción de Keynes: efectos "desastrosos". En este contexto, ¿qué significa desastroso? En breve, un conjunto de efectos tales como: i) caída en los niveles del ingreso nacional real; ii) reducción en los salarios reales; iii) aumento de la tasa de desocupación; iv) elevación de la tasa de interés y caída de la tasa de beneficio empresarial. Por lo mismo, caída en los niveles de inversión y del ritmo de crecimiento a futuro. En general, ningún economista -que sepamos- considera positivos a tales efectos.

A lo señalado, habría que agregar: esos efectos no sólo son negativos. También son no-neutrales. O sea, perjudican a la mayoría pero un sector social sí se beneficia: se trata de aquella fracción del capital que gira en torno al capital-dinero de préstamo y cuyo acceso a la plusvalía asume la forma del interés o de ganancias especulativas. Algo que en los últimos años (primera década del siglo xxi) y la crisis del 2008 ha quedado en abierta evidencia. ${ }^{53}$

Políticas con efectos tan desastrosos (ésta es una "verdad de hecho") no podrían preservarse en un mundo racional y democrático. ¿Por qué, entonces, se reproducen una y otra vez? En nuestra opinión, el criterio de Keynes es impreciso y, al final de cuentas, erróneo. Expliquemos: los efectos desastrosos no lo son para todos. Para un sector social, los efectos resultan muy útiles. Y si este sector se impone, es porque tiene fuerza: las políticas del FMI, jamás han sido decididas a partir de la aclamación popular.

De lo expuesto podemos deducir algunas moralejas que no por obvias son menos importantes: i) las teorías económicas y las políticas que de ellas se derivan, no son neutrales (en un sentido social y político); ii) por lo mismo, no se puede hablar de políticas económicas buenas o malas en abstracto. Lo bueno para un sector social, es malo para otro; iii) teorías como el neoclasicismo walrasiano rechazan las hipótesis ii) e i). Pero entonces, debería someterse al test empírico y aceptar lo que éste dice: las consecuencias de su aplicación son desastrosas. Y, por ello, desechar la teoría en cuestión. Por cierto, esto no tiene lugar.

Al aplicarse, la teoría provoca efectos que no se explicitan (al revés, de palabra se rechazan) pero que de hecho sí se buscan: se dice una cosa y se hace otra.

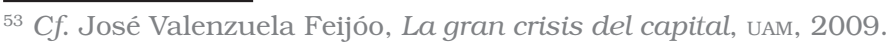


La teoría, por ello se vuelve a aplicar una y otra vez. Y para ciertos propósitos y para ciertos grupos sociales, resulta útil y eficaz. ${ }^{54}$ Ahora bien, si tomamos como patrón de referencia los propósitos públicos, oficiales y pudibundos, es claro que la evidencia empírica rechaza a la teoría. Pero si consideramos como hipótesis de base los propósitos ocultos o latentes, es claro que resulta exitosa. Todo esto, es muy impropio de la ciencia y sí muy típico de las ideologías mistificadoras. Por lo mismo, se trata de evidencias que apuntan a revelar la auténtica funcionalidad y el real estatuto del neoclasicismo walrasiano: poca o ninguna ciencia, formas de razonamiento usualmente muy sofisticadas y un contenido ideológico mistificador bastante extremo. En algún sentido, hay aquí algo así como una reedición de la teología medieval aristotélica, aquélla que el dr. Angélico consolidara con inigualable rigor y sistema.

Podríamos resumir muy gruesamente lo expuesto en dos hipótesis fundamentales: a) la corriente teórica dominante -la neoclásica- hoy proclama una visión metodológica empirista (neopositivista o popperiana), pero de hecho funciona en términos básicamente apriorísticos; b) la misma corriente declara que su teorización es positiva pero, en los hechos, el grueso de su argumentación se refiere a un "deber ser" nada de misterioso. En breve, empirismo de palabra y apriorismo de hecho; positividad de palabra y normatividad de hecho. Una forma muy científica y un contenido sustantivo bastante politizado y apologético.

Estas hipótesis pueden y deben ser discutidas. Y si ellas son verdaderas, no pueden provocar una aprobación unánime. De momento nos basta su simple señalización. Y agregar que ambigüedades y equívocos metodológicos como los mencionados por lo menos dan pábulo a alguna (?) duda sobre el pretendido carácter científico de nuestra disciplina.

\section{Conclusiones preliminares}

Hemos mencionado algunas características que asume el trabajo académico en el seno de nuestra disciplina. Este repaso, por breve y rápido que haya sido, nos permite efectuar al menos cuatro conclusiones: primero, el estatuto científico de la disciplina resulta bastante dudoso. De la economía se ha dicho que es la "más dura de las ciencias blandas" pero así y todo, a veces

\footnotetext{
${ }^{54}$ De acuerdo a una visión pragmática algo burda, será verdadera en tanto es útil. Esta distorsión es muy frecuente en el campo empresarial y publicitario. Pero, amén de cínica, es falsa de punta a rabo. Se va de lo verdadero a lo útil (para algunos) y no al revés.
} 
su dureza no parece superar la de un puré de patatas; segundo, el contenido ideológico-doctrinario de la disciplina suele ser bastante más fuerte y elevado del que se acostumbra admitir; tercero, en tal contexto, la elección de programas curriculares resulta compleja y no fácil de efectuar acudiendo a criterios objetivos, claros, e indisputables; cuarto, lo que para nosotros sería quizá la enseñanza primordial a extraer: la necesidad de ser extremadamente cauteloso en la evaluación de las diversas escuelas y corrientes del pensamiento económico. Más aún, la necesidad de abandonar esa actitud de soberbia y auto-complacencia con que a veces observamos los logros de lo que denominamos -no con muchas razones- nuestra "ciencia económica”. Para el caso, nada mejor que recordar el consejo (o deseo) manifestado por Keynes: "si los economistas pudieran arreglárselas para que se pensara de ellos que son gente humilde y competente en un mismo nivel con los dentistas, sería espléndido". ${ }^{55}$

\section{Despejando equívocos}

Y permítasenos despejar anticipadamente un malentendido posible. Hemos enfatizado algunos aspectos que caracterizan a la teoría económica y que provocan dudas muy fuertes sobre su pretendido estatuto científico. Implícitamente, nuestro punto de referencia son las ciencias calificadas como "duras": matemáticas, física, química. Habría, en consecuencia, que admitir: a) no debemos pretender una relación de identidad entre $v g$. la física y la economía. Aquí, no solamente nos encontramos con las obvias peculiaridades que impone el diferente objeto de estudio. También, está el hecho aún más decisivo de que la economía no podría ser una ciencia natural sino social, lo cual provoca diferencias bastante sustantivas en los modos del quehacer científico; ${ }^{56}$ b) no debemos crear una imagen fetichizada y falsa de las ciencias naturales. En éstas, no existen unanimidades completas y los mecanismos de verificación y de reemplazo de teorías no son nada de idílicos o sencillos y prístinos. Hasta en las mismísimas matemáticas podemos observar escuelas que disputan en torno a problemas básicos en polémicas que se alargan por décadas: por ejemplo, entre la escuela formalista (Hilbert), la logicista (Russell-Whitehead) y la intuicionista (Brouwer).

55 J. M. Keynes, "Essays in Persuasión", en The Collected Economic Writings, vol. 9, p. 332. Macmillan, London, 1973.

${ }^{56}$ La escuela austriaca ha enfatizado mucho este aspecto, pero ha arribado a conclusiones cuasi-románticas y subjetivas. Es decir, de la constatación de la peculiaridad, terminan por eliminar el contenido científico (genérico) del saber sobre la sociedad. 
Una última consideración apunta a la necesidad de no confundir nuestras observaciones con una especie de masoquismo obsesivo y gratuito. En breve, no pretendemos desconocer los progresos de la disciplina, en el plano del rigor formal, del posible test empírico e inclusive en los contenidos teóricos sustantivos. A partir de la macro keynesiana y del desarrollo de los modelos econométricos, los avances son genuinos y significativos. Que los modelos fallan es cierto, pero sería del todo reaccionario tomar esos errores para paralizar la investigación y no como estímulo para superar insuficiencias y debilidades. En corto, el progreso existe pero eso no nos permite sostener que la economía ya es una ciencia. 